\title{
Considerations Regarding the Influence of the Gaseous Nitriding of the AISI1212 Steel on the Behavior at Atmospheric Corrosion
}

\author{
Maria STOICANESCU \\ Transilvania University of Brasov, Romania, stoican.m@unitbv.ro
}

\begin{abstract}
Given the wide field of use of the AISI1212 steel as well as the conditions required by its exploitation, we have considered a study to look at the possibilities of improving the mechanical properties and increasing the corrosion resistance up to the degradation factors of the metallic structure. This consisted in performing the thermochemical treatment of nitriding in a gas mixture, which has the effect of increasing surface hardness, long-term vibration resistance and obtaining an anti-corrosive protective layer. We aimed to obtain superior characteristics for it through the diffusion of nitrogen in the layer, in comparison with the classical heat treatment $[1,2]$.
\end{abstract}

\section{Keywords}

diffusion process, superficial layer, microhardnes, corrosion

\section{Introduction}

Nitriding is frequently performed to increase the wear resistance by increasing the surface hardness. The nitrides of the alloying elements $\mathrm{Cr}, \mathrm{Mo}, \mathrm{Al}$, and respectively the related carbonitrides have high hardness. As a result, construction steels with a medium carbon content are used for nitriding. Also the hardness is higher as the temperature of the thermochemical treatment is lower. In these conditions, surface hardness of 1000-1200 HV are made for alloyed steels and 600-800 HV for non-alloyed steels, at the same carbon content. The obtained layer thicknesses result at a low diffusion rate of approx. 0.01 $\mathrm{mm} / \mathrm{h}$. At the same time with the increase of the surface hardness, there is also an increase of the resistance to oxidation and corrosion. If the main purpose of the nitriding becomes to increase the oxidation and corrosion resistance then the operating temperature can be increased. The process can also be applied to cheaper, non-alloyed steels, with a carbon content of $0.1-0.2 \%$.

Mechanical stresses with temperature shocks and corrosion are the main factors that lead to the deterioration of the improvement steel parts. All these undesirable effects have a common feature: they appear predominantly or exclusively in the superficial layer of the parts. For these reasons, we considered it necessary to investigate the physico-chemical processes that appear in the superficial layers. The problems of hardness, fatigue and corrosion are solved by using thermal and thermochemical treatments in most cases; these allow obtaining the necessary operating properties as a result of the transformations that occur in steel upon its heating-cooling [5-7].

Gas nitriding is performed at temperatures between 480 and $600{ }^{\circ} \mathrm{C}$ and is applied on non-alloyed and alloyed construction steels [5]. The nitrogen source in these processes is ammonia (NH3). Under the process conditions, the ammonia adsorbed on the surface of the treated steel undergoes a gradual dissociation and thus the atomic nitrogen formed diffuses into the steel as shown in Figure 1a; Figure $1 \mathrm{~b}$ shows the Fe-N diagram [3]. The structure of the nitrated layer depends on the temperature values, the nitrogen potential, according to the Lehrer diagram [4] and the used steel [5].

Data which was experimentally obtained was considered in order to determine the diffusion coefficient when nitriding weakly alloyed construction steels, according to Table 1 and Figure 2 .

Table 1 contains the data obtained for the thermochemical nitriding treatment for AISI1212 steel at $590^{\circ} \mathrm{C}$.

Table 1. Thermochemical data of nitriding treatment

\begin{tabular}{|c|c|c|c|c|c|}
\hline No. crt. & Steel & $\mathrm{t}\left[{ }^{\circ} \mathrm{C}\right]$ & $\mathrm{x}[\mathrm{mm}]$ & $\tau[\mathrm{h}]$ & $\mathrm{D} \cdot 10^{-7}\left[\mathrm{~cm}^{2} / \mathrm{s}\right]$ \\
\hline 1 & AISI1212 & 590 & 0.6 & 6 & - \\
\hline
\end{tabular}



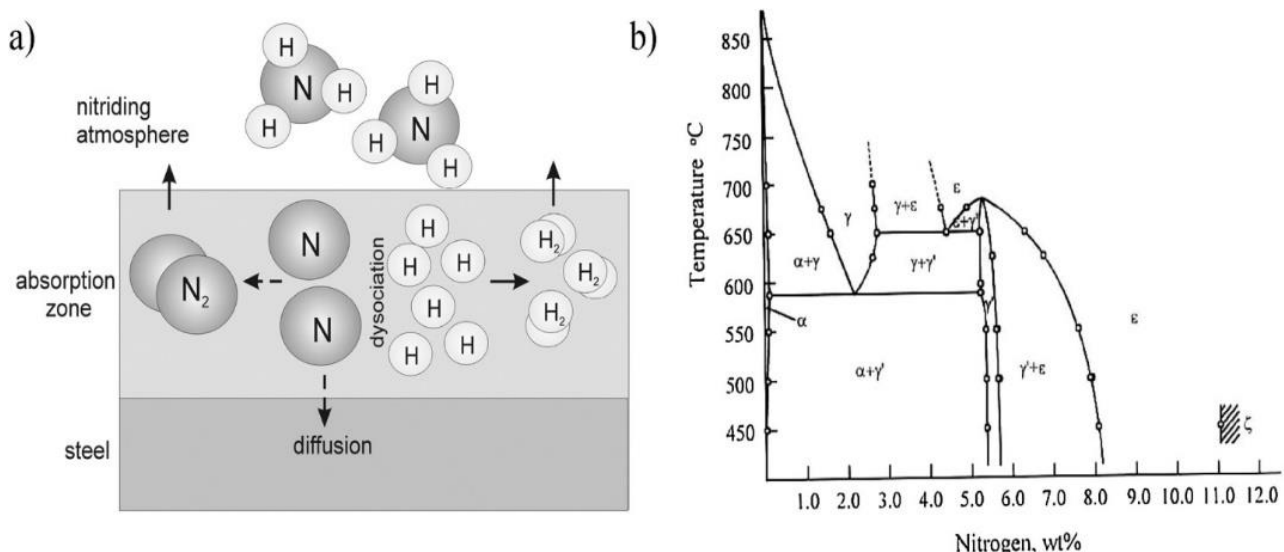

Fig. 1. a- Schematic diagram of the nitriding process, and b- the Fe-N phase diagram [3]

The saturation concentration of nitrogen at $590^{\circ} \mathrm{C}$ for AISI 1212 is Nsat $=1.2 \%$ and the nitrogen concentration in the initial state $\mathrm{N}_{0}=0.002 \%$.

The penetration depth was conventionally chosen as the distance at which the nitrogen content decreased to a limit value of $0.3 \%$.

Wagner proposes two computational relations depending on the concentration criterion, namely

$$
\theta_{N}^{*}=\frac{N(x, \tau)-N_{0}}{N_{p o t}-N_{0}}
$$

where $\mathrm{N}(\mathrm{x}, \tau)$ is the minimum nitrogen concentration allowed in the layer.

It turns out that: $\theta_{\mathrm{N}}=0.248$

For $0.05<\theta c<0.3$ the nitriding time is determined as follows:

where:

$$
X=\frac{\sqrt{\bar{D} \cdot \tau}}{0.37+\theta_{N}}-\frac{\bar{D}}{\beta}
$$

$X$ - desired layer thickness $=0.6 \mathrm{~mm}$;

$\beta$ - coefficient of transport speed;

$\beta=1.2 \cdot 10^{-5}[\mathrm{~cm} / \mathrm{s}]$.

Results $\tau=21960(\mathrm{sec})=6.1[\mathrm{~h}]$

\section{Method and Material}

The present paper aims to obtain superficial layers resistant to corrosion under atmospheric conditions.

A non-alloyed steel with low carbon content was used according to Table 1.

Table 1. Chemical composition of the steel

\begin{tabular}{|l|l|l|l|l|}
\hline Material & $\mathrm{C}[\%]$ & $\mathrm{Mn}[\%]$ & $\mathrm{P}[\%]$ & $\mathrm{S}[\%]$ \\
\hline AISI 1212 & $<0.13$ & $0.7-1.00$ & $0.070-0.12$ & $0.16-0.230$ \\
\hline
\end{tabular}

Table 2 shows the parameters of the thermochemical process and the obtained results.

Table 2. The parameters of the thermochemical process and the obtained results

\begin{tabular}{|l|l|l|l|l|l|l|l|}
\hline Material & \multicolumn{2}{|l|}{ The parameters of the thermochemical process } & Hardness HV0.3 & Thick \\
& $\begin{array}{l}\text { Environment gas } \\
\text { mixture }\end{array}$ & $\begin{array}{l}\text { Temp. } \\
{\left[{ }^{\circ} \mathrm{C}\right]}\end{array}$ & $\begin{array}{l}\text { Time } \\
{[\mathrm{h}]}\end{array}$ & Cooling & Layer & Core \\
AISI 1212 & $\begin{array}{l}-\mathrm{NH} 3-3.8 ;>99,98 \% \\
-\mathrm{CO} 2-4.5 ;>99,9 \%\end{array}$ & 590 & 6 & air & 264.6 & $155-203$ & 0.6 \\
\hline & & & & & & \\
$-\mathrm{N} 2-4.0 ;>99,99 \%$ & & & & & & \\
\hline
\end{tabular}


The working temperature was $590^{\circ} \mathrm{C}$ with a maintenance of 6 hours, this was chosen according to the desired hardness; these parameters influence the hardness of the layer, the hardness gradient, the wear resistance and the preservation of the core characteristics.

The process parameters are shown in Figure 2.

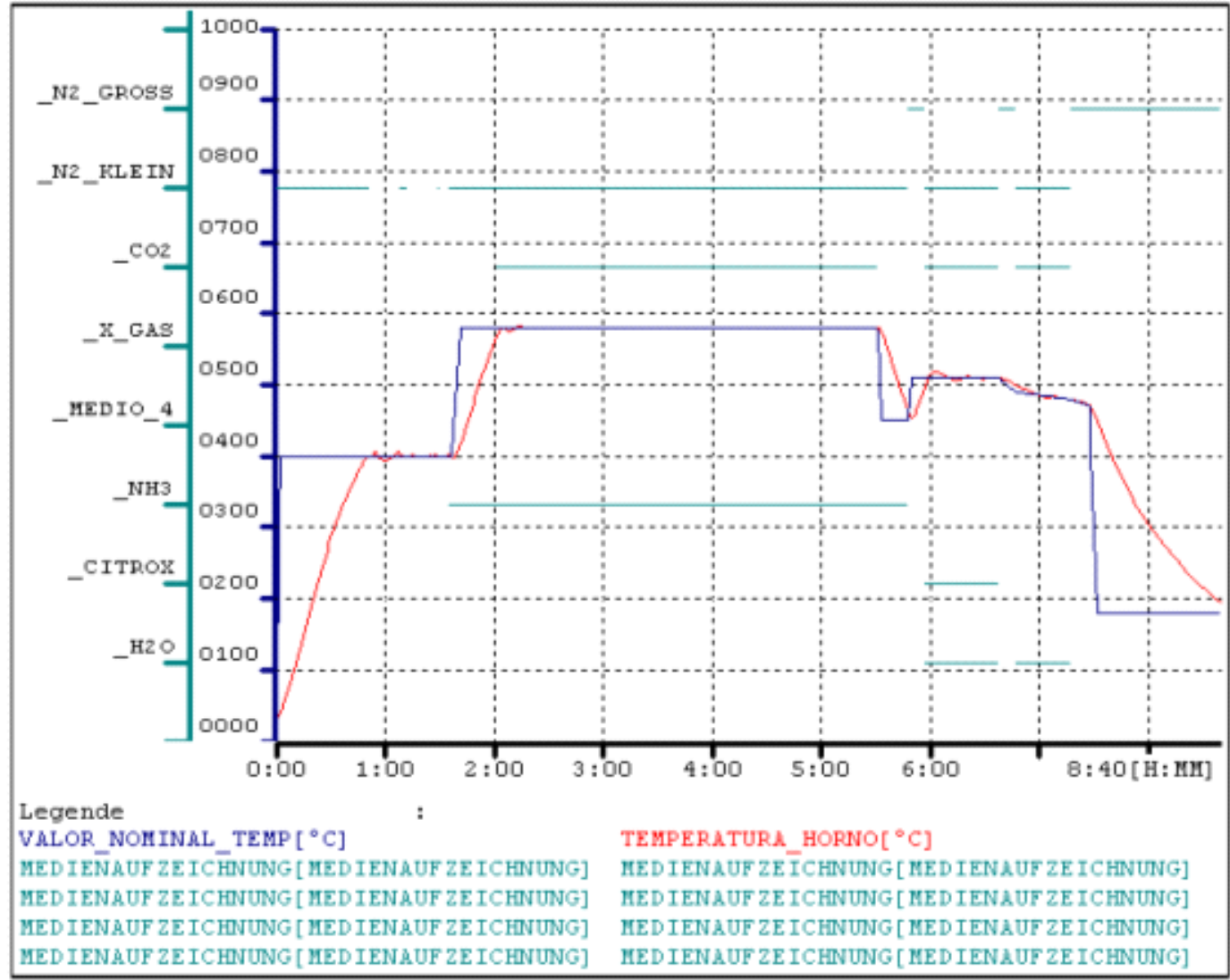

Fig. 2. Process parameters

\section{Results}

The samples thus treated (Figure 3) were prepared for the measurement of micro-hardness, metallographic analysis and corrosion resistance.
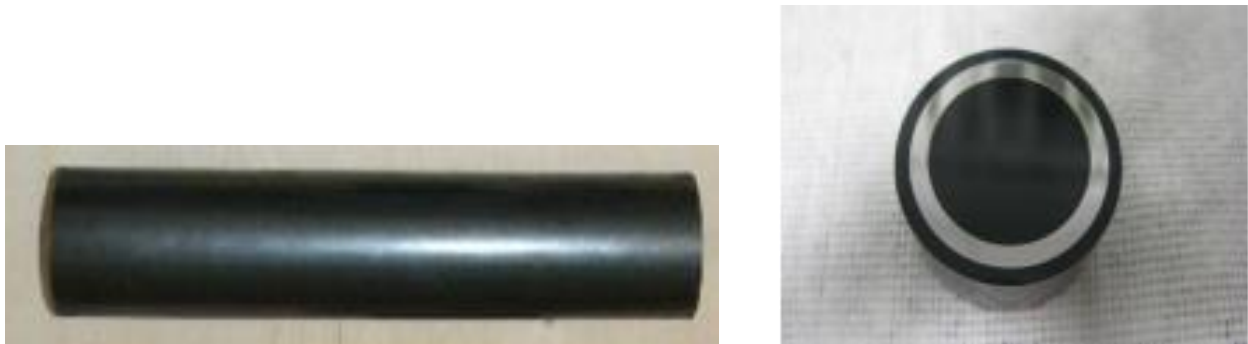

Fig. 3. Presentation of treated samples

In order to determine the thickness of the diffusion layer, a metallographic analysis was used. Figure 4 schematically shows the sequence of areas from the layers obtained on the base material.

The nitride layer $\varepsilon(\mathrm{Fe} 2-3 \mathrm{~N})$ [in the case of carbon steels Fe $2(\mathrm{C}, \mathrm{N}) 1-\mathrm{x}$ ] and $\gamma^{\prime}$-Fe4N carbonitrides are often formed and represent the outer area of the nitride layer, which is known as the white layer with iron nitrides content. In the area below the iron nitride layer, there is an area called the inner nitriding layer. It consists of nitrogen saturated ferrite with precipitates of $\gamma^{\prime}$ nitrite, while deeper it is found only nitrogen ferrite $-\alpha(\mathrm{N})[3,6]$. 


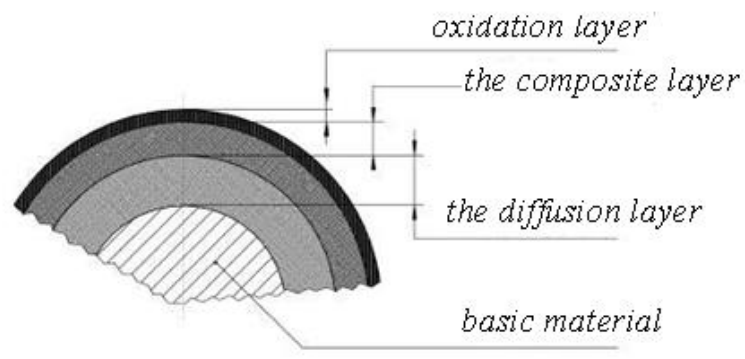

Fig.4. Layer representation on the base material

The structure of the nitrated layer is shown in Figure 5. This area consists of the $\alpha$ and $\gamma$ ' phases included in the matrix. Iron nitrides are present in the form of thin grids.
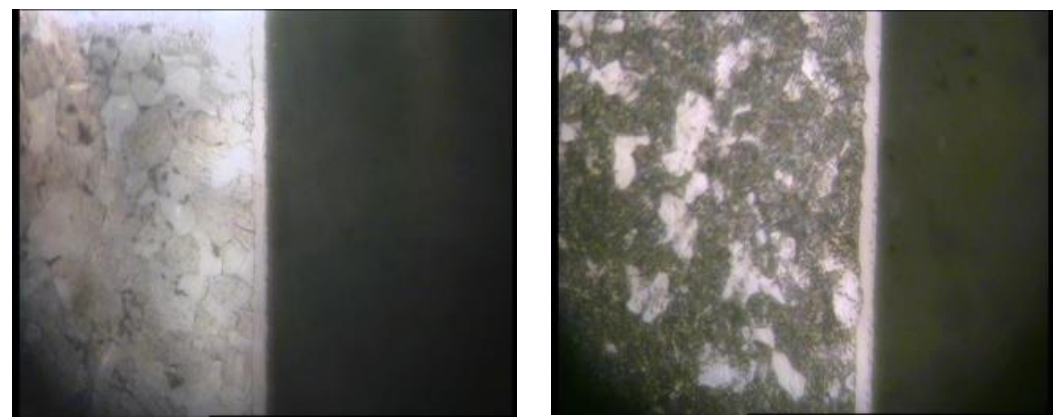

Fig. 5. The depth of nitrate layer, attack Nital, $\times 40$

The material has the oxidation layer and the nitrated layer with a thickness of 8 - $10 \mu \mathrm{m}$; the surface is smooth, without inclusions or cracks.

The thickness of the diffusion layer was determined by means of a depth micro-hardness test.

It was used a Vickers Durimeter to determine the micro-hardness, used weight - $300 \mathrm{~g}$ and pressing time $-12 \mathrm{~s}$.

The thickness of the diffusion layer (considered up to the base material) is $0.5-0.6 \mathrm{~mm}$ and the hardness of the base material is 155-203 HV0.3.

The obtained results are presented in Figures 7 and 8.
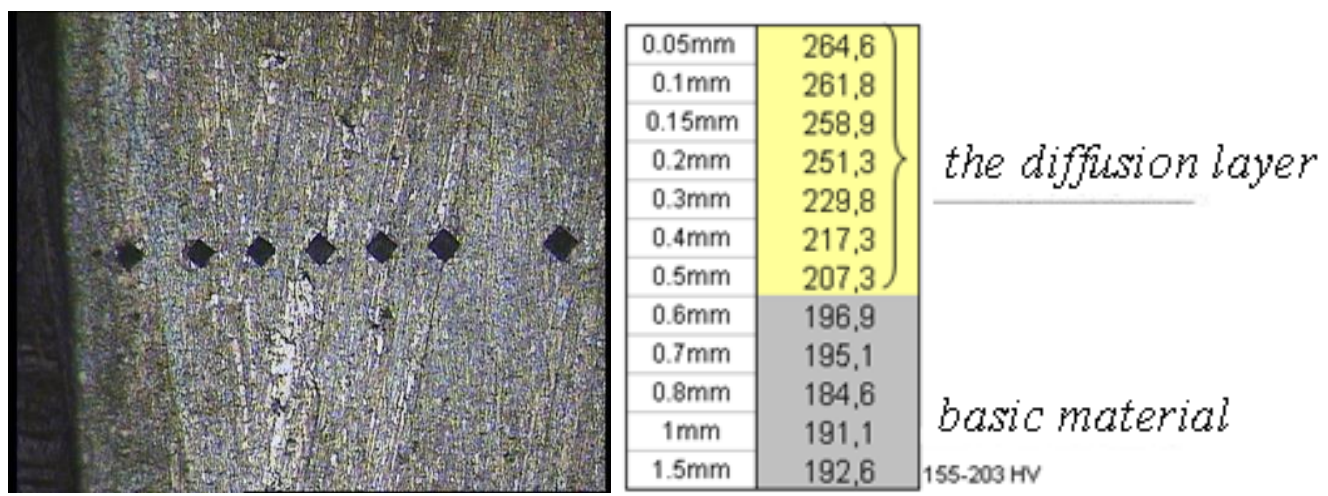

Fig. 7. The result of the diffusion layer analysis

The researches continued with the corrosion test under conditions of temperature variation.

To assess corrosion behavior, the samples were exposed to a controlled humid environment. The occurrence of corrosion and the evolution of the degree of corrosion at different time intervals were followed. The corrosion test is performed in a condensation chamber that allows control of the environment. The device allows the setting of temperature, humidity, brightness and ventilation over time intervals. 


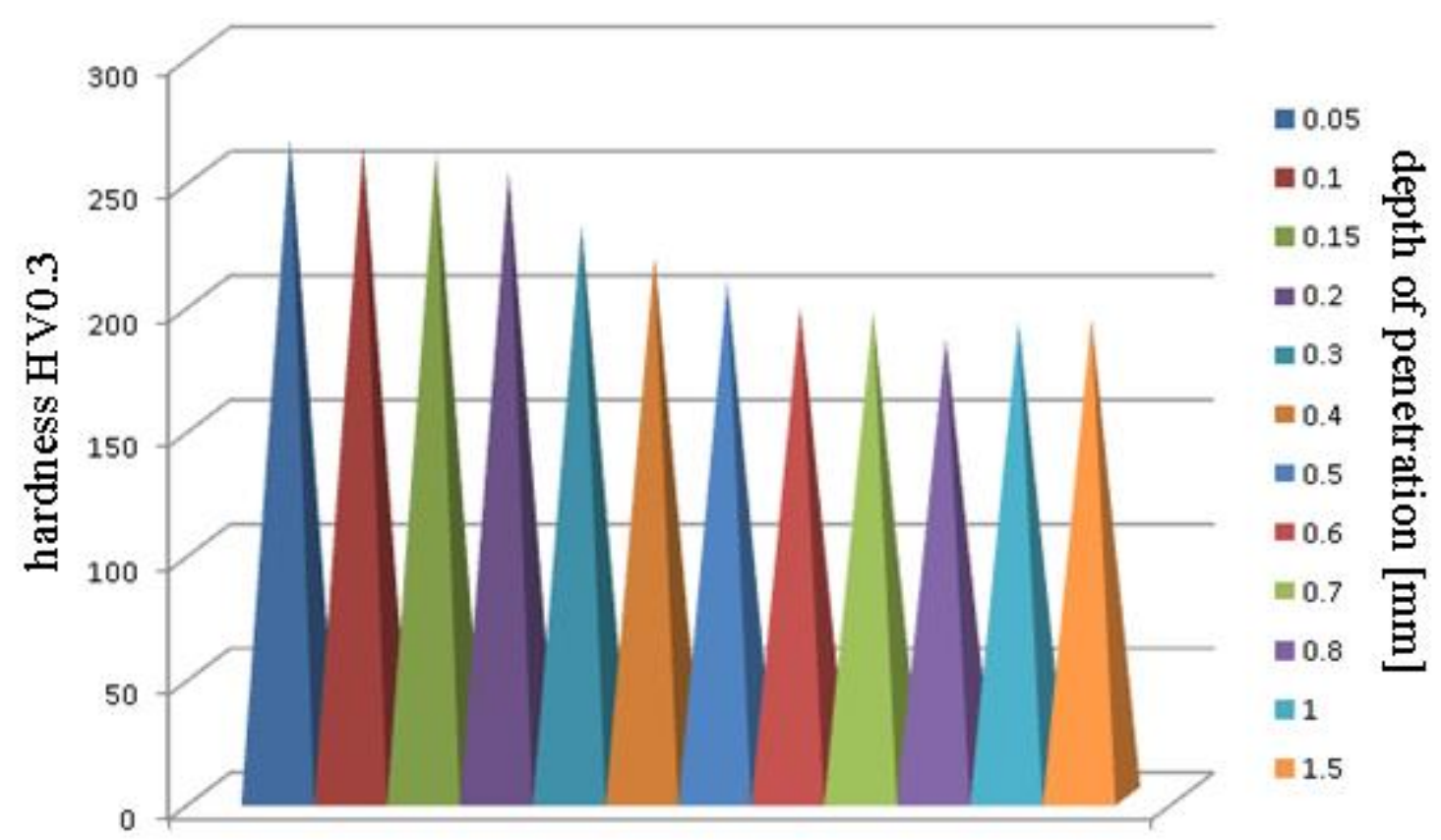

Fig. 8. Graphic representation of the depth of penetration

The device used was CLIMACELL (Figure 9) consisting of a climatic chamber that can reproduce and simulate various climatic conditions, applicable in product stability tests. The device is controlled by a system of microprocessors to operate humidification and dehumidification accompanied by strong lighting. At the same time, the temperature inside the room, the ventilation, are controlled in the same way.

The test was performed as follows: 3 cycles of $504 \mathrm{~h}$ and the results are presented in Table 2 .

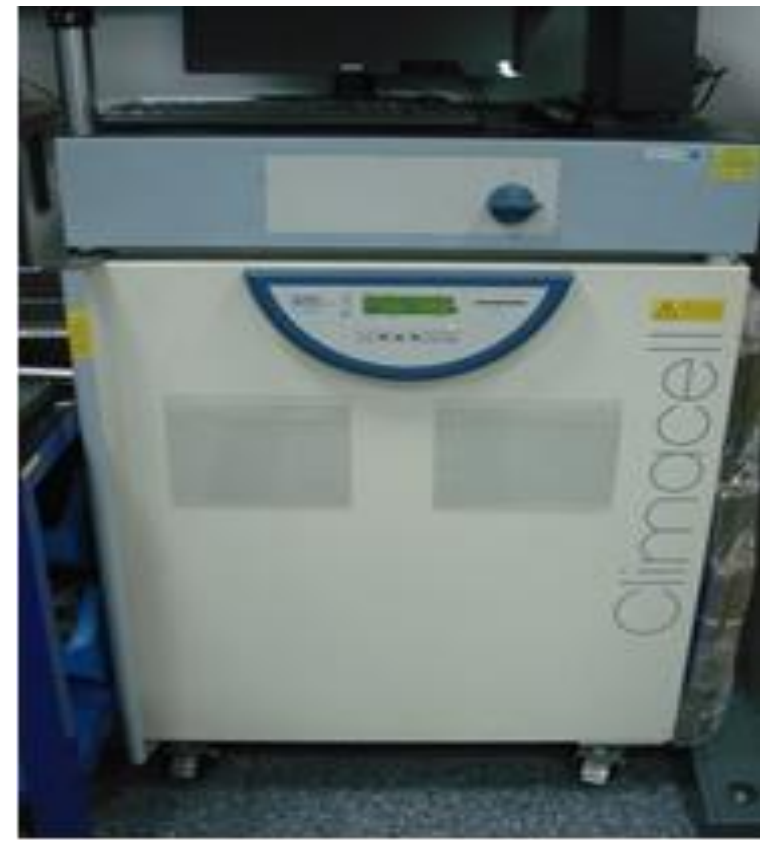

Fig. 9. CLIMACELL condensing chamber

Table 2. Test cycle description

\begin{tabular}{|c|c|c|c|}
\hline Stage & Time & Temperature & Humidity \\
\hline P00 & $1 \mathrm{~h}$ & balancing & balancing \\
\hline P01 & $84 \mathrm{~h}$ & const $25^{\circ} \mathrm{C}$ & $\mathrm{RH} 85 \%$ \\
\hline P02 & $2 \mathrm{~h}$ & const $47.8^{\circ} \mathrm{C}$ & $\mathrm{RH} 75 \%$ \\
\hline P03 & $2 \mathrm{~h}$ & const $47.8^{\circ} \mathrm{C}$ & $\mathrm{RH} 65 \%$ \\
\hline P04 & $2 \mathrm{~h}$ & const $47.8^{\circ} \mathrm{C}$ & $\mathrm{RH} 55 \%$ \\
\hline P05 & $2 \mathrm{~h}$ & const $47.8^{\circ} \mathrm{C}$ & $\mathrm{RH} 45 \%$ \\
\hline P06 & $2 \mathrm{~h}$ & const $47.8^{\circ} \mathrm{C}$ & $\mathrm{RH} 35 \%$ \\
\hline P07 & $2 \mathrm{~h}$ & const $47.8^{\circ} \mathrm{C}$ & $\mathrm{RH} 25 \%$ \\
\hline P08 & $2 \mathrm{~h}$ & const $47.8^{\circ} \mathrm{C}$ & $\mathrm{RH} 20 \%$ \\
\hline P09 & $70 \mathrm{~h}$ & const $47.8^{\circ} \mathrm{C}$ & $\mathrm{RH} 20 \%$ \\
\hline P10 & Oh & const $25^{\circ} \mathrm{C}$ & $\mathrm{RH} 20 \%$ \\
\hline
\end{tabular}

The results of the corrosion test under temperature stress are shown in Figures 10-13.

In this latest case it can be observed how the rust has managed to penetrate the structure of the material, presenting a high degree of degradation.

The nitrided material passed the corrosion test showing its resistance over time. 


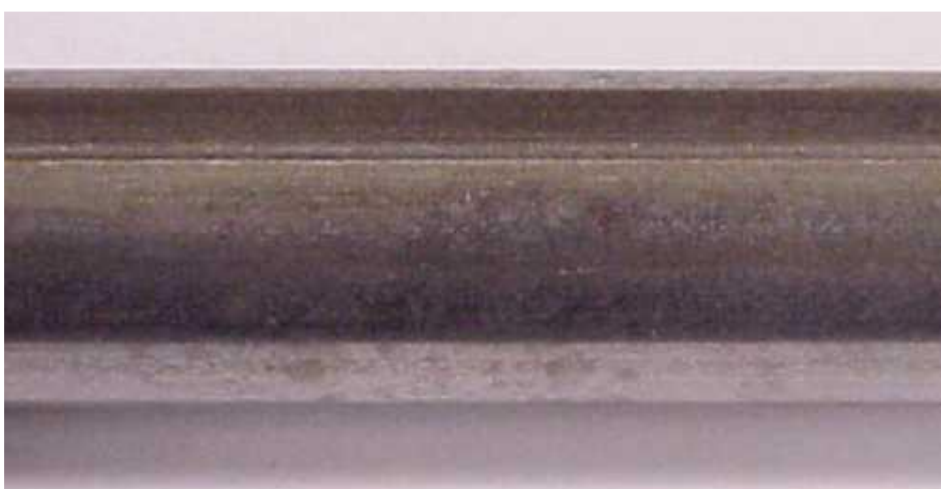

Fig. 10. Completion of cycle 1: No rust marks

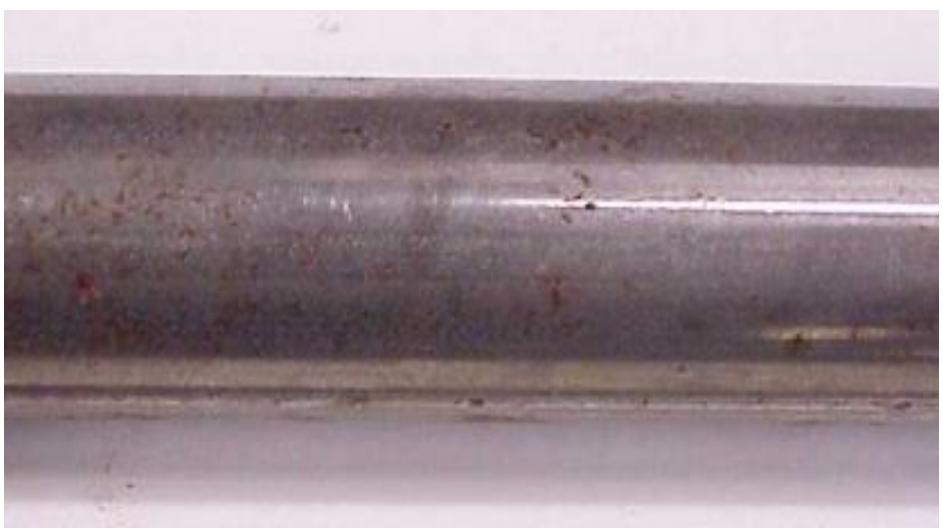

Fig. 11. Completion of cycle 2: The appearance of corrosion pores

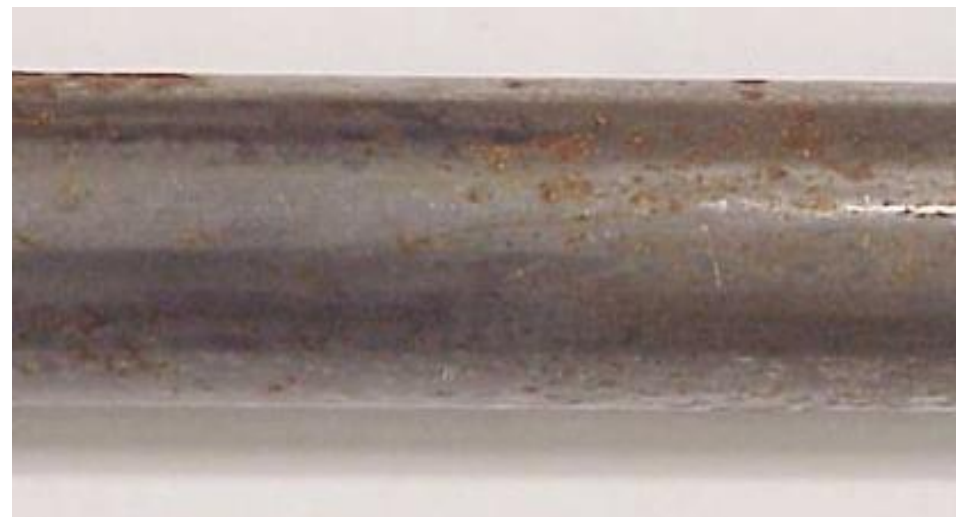

Fig. 12. Completion of cycle 3: The corrosion pores have not spread on the surface

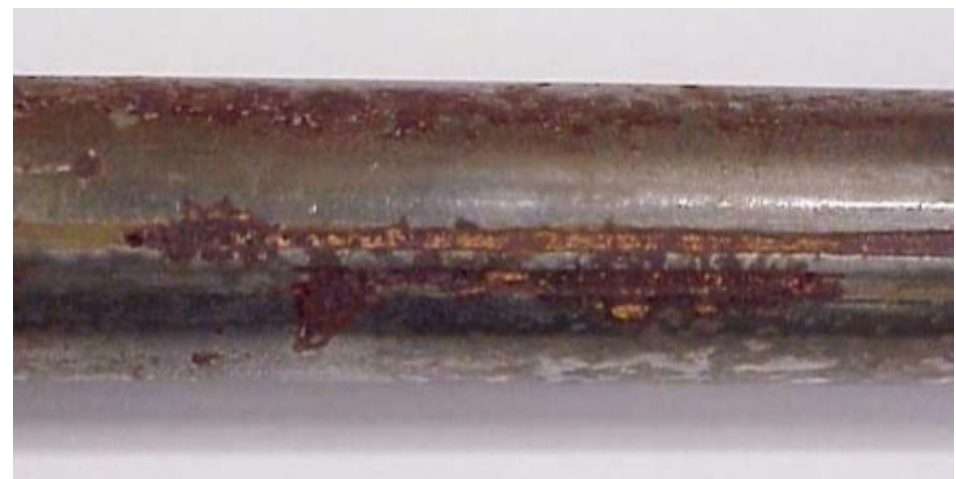

Fig. 13. Reference: tube that has not been nitrided and has undergone the same corrosion test (3 cycles) 


\section{Conclusions}

The research conducted on AISI1212 steel subjected to gaseous nitriding has led to the following:

- during 6 hours of nitriding at a temperature of $590{ }^{\circ} \mathrm{C}$, a layer of iron nitrogen with a total thickness of $0.6 \mathrm{~mm}$ is formed, consisting of $\varepsilon$ and $\gamma^{\prime}$ nitrites;

- the outer zone of nitride has a hardness of $264.6 \mathrm{HV}$;

- the area of the layer near the substrate is made up of a mixture of $\varepsilon$ and $\gamma^{\prime}$ nitrites and has a lower hardness of $207.3 \mathrm{HV}$;

- the iron carbides of the pearlite represent a preferred site for the nucleation of steel nitrides, resulting in the Fe3 (C, N) 1 - $x$ type of phase;

- nitrided samples have a much better corrosion behavior compared to the control sample.

\section{References}

1. Giacomelli I., Drugă L., Samoilă C., Bot D. (2000): Tehnologii neconvenționale cu transformări de fază (Unconventional technology with phase transformations). Lux Libris, ISBN 973-9240-66-6, Brasov, Romania (in Romanian)

2. Torodoc N., Giacomelli I. (2008): Special heat and thermochemical treatments of high speed tools steel. 17-th International Metallurgical and Materials Conference, Metal 2008, Czech Republic, Tanger, ISBN 978-80-2541987-8, p. 102-107, http://metal2014.tanger.cz/files/proceedings/metal 08/Lists/Papers/097.pdf

3. Kucharska B., Michalski J., Wójcik G. (2019): Mechanical and microstructural aspects of C20-steel blades subjected to gas nitriding. Archives of Civil and Mechanical Engineering, ISSN 1644-9665, Vol. 19, is. 1, p. 147-156, https://doi.org/10.1016/j.acme.2018.09.006

4. Lehrer E. (1930): Über das Eisen-Wasserstoff-Ammoniak-Gleichgewicht. Z. Elektrochem., Vol. 36, is. 6, p. 383-392, https://doi.org/10.1002/bbpc.19300360606

5. Ratajski J., Olik R. (2010): Development of nitrided layer during nitriding of steel. Advanced Materials Research, ISSN 1662-8985, Vol. 83-86, p. 1025-1034, https://doi.org/10.4028/www.scientific.net/AMR.83-86.1025

6. Smolik J., Walkowicz J., Tacikowski J. (2000): Influence of the structure of the composite: 'nitrided layer/PVD coating' on the durability of tools for hot working. Surface and Coatings Technology, ISSN 0257-8972, Vol. 125, is. 1-3, p. 134-140, https://doi.org/10.1016/S0257-8972(99)00593-9

7. Michalski J.Z., Iwanow J., Tacikowski J., Sułkowski I., Wach P., Tarfa T.N., Tymowski J. (2004): Anti-corrosion nitriding, with post-oxidation and inhibitor impregnation, and its industrial applications. Heat Treatment of Metals, ISSN 0305-4829, Vol. 31, is. 2, p. 31-35 